\title{
DAgARAgu WOMEN BUILD KEePing PLACE
}

The Aboriginal Sacred Sites Protection Authority has employed me as their female anthropologist to help Aboriginal women who are worried about their law and country. I am to be based in Alice Springs and will work from there visiting communities in the central areas of the Northern Territory.

The women of Dagaragu Aboriginal Community had asked the Aboriginal Sacred Sites Protection Authority to provide them with a women's shed to store their secret sacred objects. The women had been worried about their law and the objects that made their law and country strong. I drove with a friend to Dagaragu last week and with the women we built the shed. As this is women's business we had to clear the ground, erect the shed and make the concrete floor by ourselves... it took several women using power tools and strength to build the shed. It took us three days from start to finish and although it was tiring work everyone was satisfied once the shed was finished. The women performed a corroboree for the shed, no photos can be shown of this as it is secret women's law. I think that it is very important that women have the opportunity to discuss any problems or worries they might have for their country, sacred sites and law with a female anthropologist.

The women's shed is an example of how Aboriginal women and the Aboriginal Sacred Sites Protection Authority can work together to help keep strong women's law and country. If I can be of any help to other communities please contact me at:-

\author{
Aboriginal Sacred Sites Protection Authority$$
\text { G.P.O.Box } 1890
$$$$
\text { Darwin, NT } 5794
$$

(Phone: (089) 81 4700)

Kim Doohan

* From Yulngu Magazine Vol.3 No.1 July 83. Yulngu Association, Pearce street, Katherine, NT 5780 